\title{
Upgraded EMC Modelling of Dual Die Structure
}

\author{
Boyuan Zhu, Junwei Lu, Sascha Stegen \\ School of Engineering, Griffith University \\ Brisbane, QLD 4111, Australia \\ boyuan.zhu@student.griffith.edu.au \\ j.lu@griffith.edu.au \\ Sascha.stegen@student.griffith.edu.au
}

\author{
Erping Li \\ Electromagnetics and Electronics Division \\ Institute of High Performance Computing \\ Singapore 689048n \\ elelep@nus.edu.sg
}

\begin{abstract}
Due to the variety of internal structures applied in different processors, EMC modelling should also be upgraded correspondingly. This paper presents an upgraded EMC simulation model of dual die structure which is originated from the IEEE electromagnetic challenging problem 2000-4 for conventional CPU with heatsink. The simulation results are verified by measurement with a fabricated model. Furthermore, a consequent benchmark will be provided.
\end{abstract}

\section{Keywords-EMC; Modelling; Dual Die; Benchmark}

\section{INTRODUCTION}

Driven by diverging requirements of IC manufacturers and customers, the needs of characterization in EMC performance of integrated circuits (ICs) are more and more important. So far as high performance integrated circuits developing, different expectations come from customers requiring IC designs to achieve specific EMC performances. Currently, IC manufacture is facing series of troubles. Among most advanced integrated circuits, processor is usually the core in a high performance electronic device. It is also recognized as an ultimate source of electromagnetic interference in the system. Therefore, this makes EMC predicting on processor become much critical, however, much difficult as well.

Proposed by the joint IEEE/EMC Society Technical Committee (TC-9) and Applied Computational Electromagnetic Society (ACES) [1], some specific electromagnetic standard challenging problems have been broad studied recently. These problems provide EMC engineers and vendors with a common standard of determining the validity and accuracy on their EM modelling. One of the conventional challenging models 2000-4, gives an electromagnetic model on CPU and its heatsink which has contributed to recent researches. However, it will no longer be effective any more when multi-die packages spread in the industry. Consequently, an upgraded model is presented for CPU of dual dies with heatsink based on amount of previous researches [2]-[6], as shown in Figure 1.

The model constructed in this paper presents how efficient a dual die CPU could be acting as an antenna creating electromagnetic interference by its structure. In order to verify the results of simulation, a test model is manufactured with the same setup in simulation. After that, validation is continued with a series of electromagnetic measurements. Reflection coefficient, input impedance, near-field power measurement are undertaken with proper electromagnetic probes, analyzers and other relative equipments. Results from simulation and measurement contribute to the consistency with acceptable minor error. An upgraded benchmark for CPU with a heatsink challenging problem may therefore be proposed.

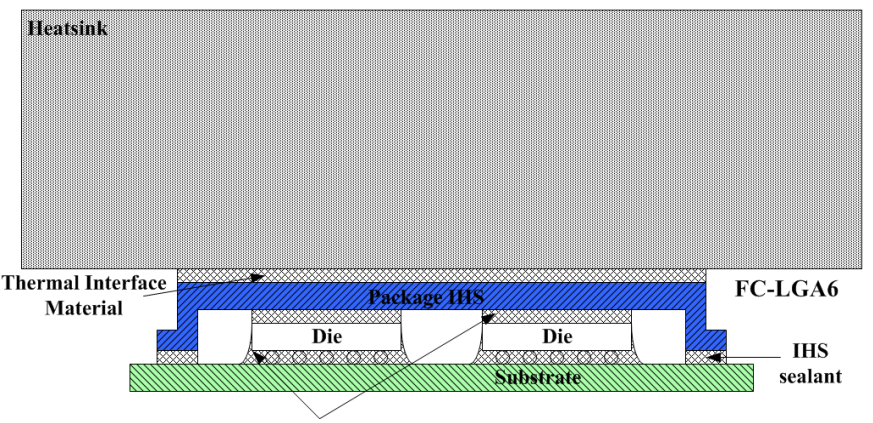

Die Attach Material

Figure 1. Transverse view of Intel Dual Die processor with heatsink [6]

\section{SimUlation MODEL}

Starting with simulation modelling, the whole structure is constructed according to a released document [7]. Certain assumptions are made on parameters which are classified as intellectual properties. The physical chip model consists of substrate, dies, Integrated Heat Spreader (IHS), Thermal Interface Material (TIM), heatsink and other adhesive materials which are included in the simulation model. Modification and simplification are implemented to reduce the mesh complexity which could save simulation time and resources. The bottom of the substrate is grounded and two lump ports are extracted from it to give two internal excitations separately, so as to simulate two dies' actions inside the chip. Two probes are standing through the substrate and dies acting as the internal connections. After implementing the extraction, the final model is illustrated in Figure 2 (a) and Figure 2 (b).

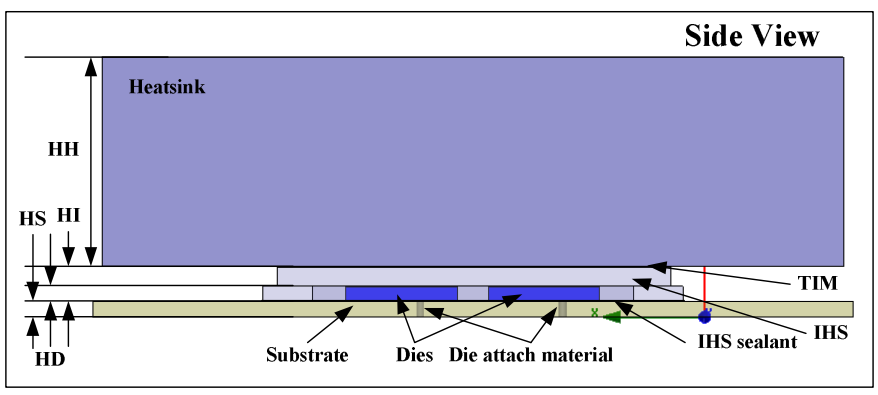

(a) Side view of model for a dual die processor 


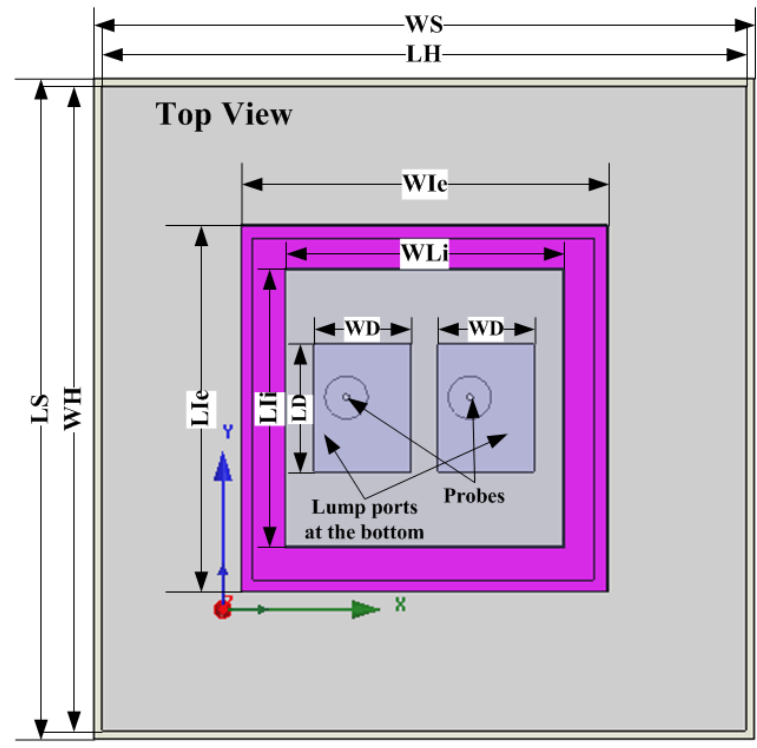

(b) Top view of model for a dual die processor

Figure 2. Simulation model of a dual die processor with heatsink

From an antenna point of view, as it is depicted, substrate is extended to satisfy the need of effective ground plane. As it is mentioned in [8], when a finite ground plane is used for practical consideration, size of ground plane should be greater than the patch dimensions by approximately six times the substrate thickness all around the periphery so that results are similar to the one using infinite ground plane. As a result, square size of $61.5 \mathrm{~mm} \times 61.5 \mathrm{~mm}$ is applied to the ground plane in this application. Detail of die size at one Intel commercial quad core chip is found in [9] with $107.0 \mathrm{~mm}^{2}$ each die, therefore, assumption is made on the model closing to the real data which is $9.0 \mathrm{~mm} \times 11.9 \mathrm{~mm}$. The structure specification is also detailed in TABLE I.

TABLE I Structure SpecificAtion of InTEL DuAl DiE Process

\begin{tabular}{|c|c|c|c|}
\hline Name & Min & Typical & Max \\
\hline Height of Heatsink (HH) & & Variable & \\
\hline Height of IHS (HI) & & $1.65 \mathrm{~mm}$ & \\
\hline Height of Die (HD) & & $1.15 \mathrm{~mm}$ & \\
\hline Height of Substrate (HS) & & $1.25 \mathrm{~mm}$ & \\
\hline Depth of TIM & & $0.1 \mathrm{~mm}$ & \\
\hline Depth of Die attach material & & $0.1 \mathrm{~mm}$ & \\
\hline Depth of IHS sealant & & $0.1 \mathrm{~mm}$ & \\
\hline Length of Heatsink (LH) & & Variable & \\
\hline Width of Heatsink (WH) & & Variable & \\
\hline Length of Die (LD) & & $11.9 \mathrm{~mm}$ & \\
\hline Width of Die (WD) & & $9.0 \mathrm{~mm}$ & \\
\hline Length of Substrate (LS) & $37.45 \mathrm{~mm}$ & $37.5 \mathrm{~mm}$ & $37.55 \mathrm{~mm}$ \\
\hline Width of Substrate (WS) & $37.45 \mathrm{~mm}$ & $37.5 \mathrm{~mm}$ & $37.55 \mathrm{~mm}$ \\
\hline Length of IHS external (LIe) & $33.9 \mathrm{~mm}$ & $34 \mathrm{~mm}$ & $34.1 \mathrm{~mm}$ \\
\hline Width of IHS external (WIe) & $33.9 \mathrm{~mm}$ & $34 \mathrm{~mm}$ & $34.1 \mathrm{~mm}$ \\
\hline Length of IHS internal (LIi) & & $26 \mathrm{~mm}$ & \\
\hline Width of IHS internal (WIi) & & $26 \mathrm{~mm}$ & \\
\hline
\end{tabular}

\section{TEST MODEL AND EXPERIMENTAL ENVIRONMENT}

\section{A. Fabrication of test model}

In order to confirm validity of electromagnetic phenomenon shown from simulation, a testing model is manufactured with detail extracted from the simulation model. A practical model is presented in Figure 3. The ground plane is a very thin copper melting at the bottom of substrate and its size is extended as well. Two SMA connectors are installed connecting with excitation sources. Commercial adhesive and thermal grease are used to perform fully contact with needed parts as the real chip does.

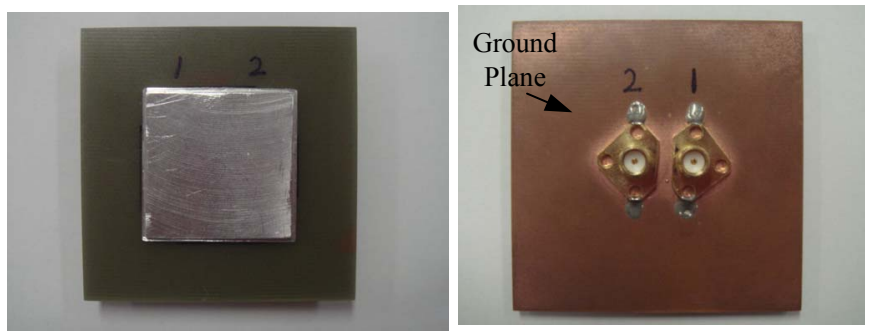

Figure 3. Top (left) and bottom (right) view of dual die test model

Figure 4 provides a detailed specification for test model fabrication and TABLE II lists material assignment.

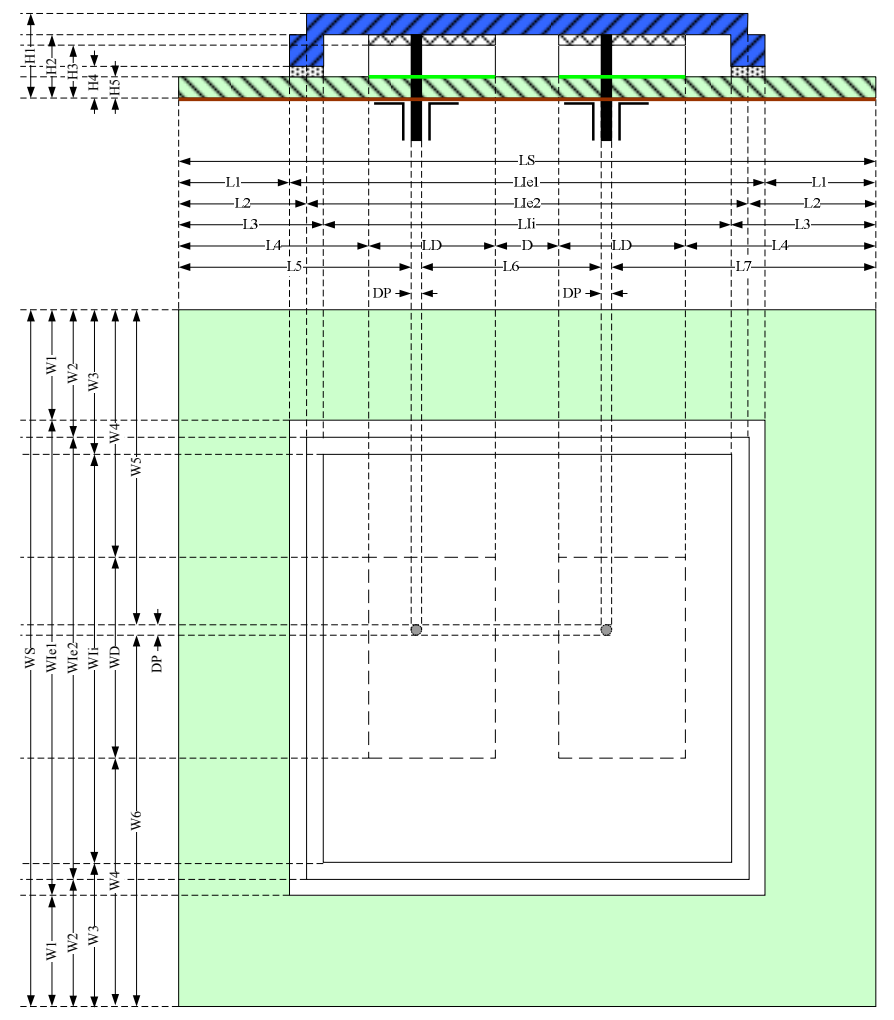

Figure 4. Fabrication specific of dual die test model

TABLE II MATERIAL ASSIGNMENT OF FABRICATION MODEL

\begin{tabular}{|l|l|c|c|}
\hline \multicolumn{1}{|c|}{ Name } & \multicolumn{1}{|c|}{ Materials } & Permittivity & $\begin{array}{c}\text { Conductivity } \\
\text { (Siemens/m) }\end{array}$ \\
\hline Groundplane & Copper & 1 & $5.8 \times 10^{7}$ \\
\hline Substrate & FR4 epoxy & 4.4 & 0 \\
\hline Die & Silicon Dioxide & 4 & 0 \\
\hline IHS & Aluminum & 1 & $3.8 \times 10^{7}$ \\
\hline Probe & Copper & 1 & $5.8 \times 10^{7}$ \\
\hline $\begin{array}{l}\text { Die Attach } \\
\text { Material }\end{array}$ & $\begin{array}{l}\text { Silver } \\
\text { contained } \\
\text { Adhesive }\end{array}$ & 1 & $6.1 \times 10^{7}$ \\
\hline
\end{tabular}




\begin{tabular}{|l|l|c|c|}
\hline Thermal Grease & $\begin{array}{l}\text { Silver } \\
\text { contained }\end{array}$ & 1.8 & 0 \\
\hline Interface & $\begin{array}{l}\text { SMA } \\
\text { connector }\end{array}$ & $/$ & $/$ \\
\hline
\end{tabular}

\section{B. Applied Measurement Setup}

Electromagnetic measurement is implemented by using ROHDEASCHWARZ vector network analyzer (VNA). This is a traditional measurement system to give global information of electromagnetic problems. The measurement frequency range is from $9 \mathrm{kHz}$ to $4 \mathrm{GHz}$. Measurement environment setup is shown in Figure 5. The test object is excited and measured through two probes connecting with VNA. Results and snapped figures are transferred to PC for further analysis. Here, reflection coefficient and input impedance are collected in the measurement.

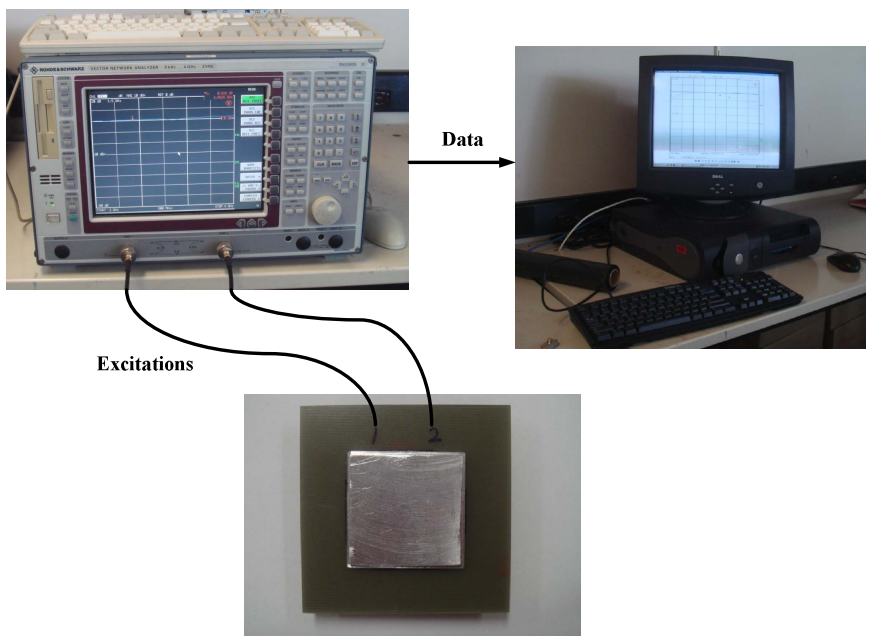

Figure 5. Electromagnetic measurement with network vector analyser

In addition, three different sizes of aluminum heatsinks are also involved in the measurement. According to Figure 6, from left to right, the size of heatsinks are $83 \mathrm{~mm} \times 64 \mathrm{~mm} \times 38 \mathrm{~mm}$, $60 \mathrm{~mm} \times 60 \mathrm{~mm} \times 39 \mathrm{~mm}$ and $101 \mathrm{~mm} \times 74 \mathrm{~mm} \times 32 \mathrm{~mm}$.

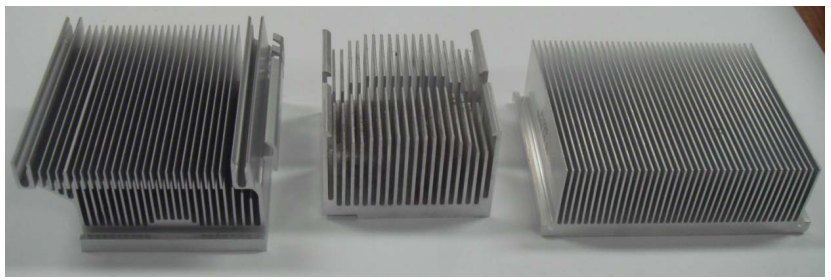

Figure 6. Three types of heatsink used in the measurement

As the resonant frequency is over $\mathrm{GHz}$ level, near-field is a better choice for field strength and absolute power measurement while far-field gives better description on the radiation pattern and antenna gain.

According to the definition of near-field and far-field [10], a boundary value of near and far field is defined as $2 \mathrm{D}^{2} / \lambda$, where $\mathrm{D}$ is the largest dimension of antenna aperture, $\lambda$ is the wavelength. When the distance $r$ between transmitting and receiving antenna satisfies $r<2 \mathrm{D}^{2} / \lambda$, it is near-field measurement. Oppositely, it is far-field measurement. A demonstration figure is provided in Figure 7. In this model, wavelength is calculated as $14.6 \times 10^{-2} \mathrm{~m}$ with resonant frequency of $2.05 \mathrm{GHz}$. Therefore, the maximum measurement distance for near-field is $5.18 \times 10^{-2} \mathrm{~m}$. Otherwise, it is in farfield range.

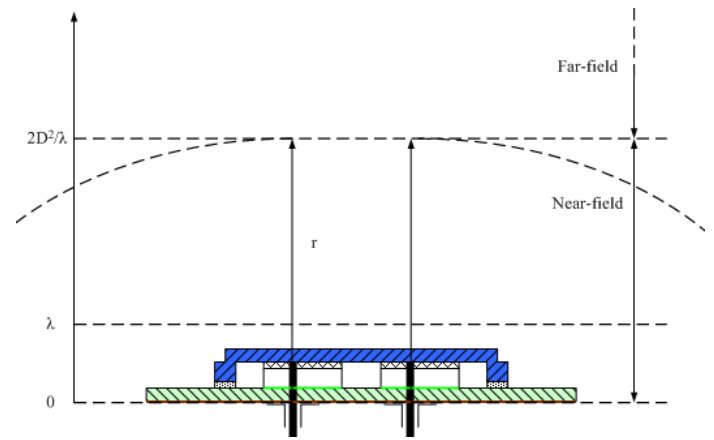

Figure 7. Definition of near-field and far-field range

However, due to limitations of test environment and equipment, measurement applied in this paper for near-field is the simplest with specific measurement antenna in a fix position upon and underneath DUT. Therefore, near-field measurement is accomplished by collaboration of AARONIA spectrum analyzer HF-6060, APRIL INSTRUMENT 2-10 $\mathrm{GHz} \mathrm{RF}$ generator and device under test (DUT), as well as corresponding software Aaronia Lcs Analyzer, shown in Figure 8.

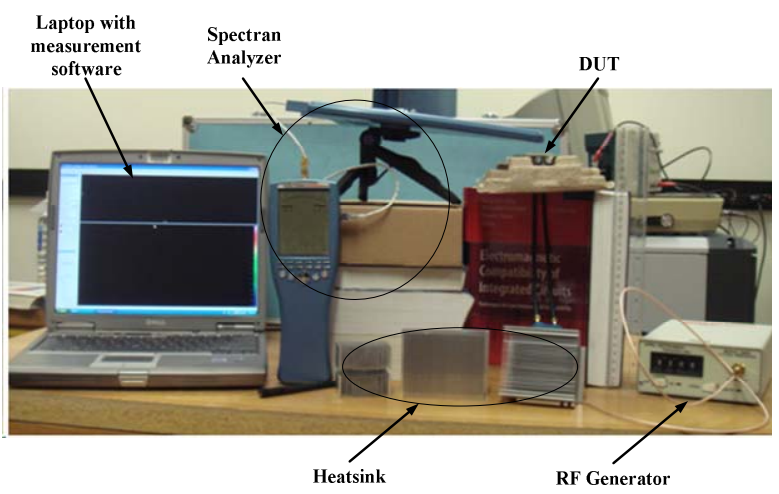

Figure 8. Near-field measurement equipments

\section{RESUlt ANALYSIS}

\section{A. Reflection Coefficient}

According to TABLE III and TABLE IV, comparison between reflection coefficient of simulation and measurement are made under corresponding configurations, at port1 and port2 respectively. Take a group of result at simultaneous excitations for instance, simulation gives a resonant frequency at $2.06 \mathrm{GHz}$ with $-18.3650 \mathrm{~dB}$ while a resonant frequency at $2.2075 \mathrm{GHz}$ with $-28.65 \mathrm{~dB}$ is collected from measurement. As listed, measured resonant frequency and reflection coefficient are slightly different from expected simulation results. Also, modelling of heatsink as a cubic box simples diversity comparing of real heatsink with fins, where also introduces some acceptable errors. However, they are still in a reasonable matched place as errors and losses introduced in calibration and measurement. Therefore, simulation and measurement are verified concurrently. 
TABLE III REFLECTION COEFFICIENT COMPARISON BETWEEN SIMULATION AND MEASUREMENT With DifFERENT CONFIGURATION AT PORT1

\begin{tabular}{|c|c|c|}
\hline \multirow{2}{*}{ Simulation Setup Environment } & \multicolumn{2}{|c|}{ Reflection Coefficient } \\
\hline & $\mathrm{GHz}$ & $\mathrm{dB}$ \\
\hline $\begin{array}{l}\text { Excitation at port1, open circuit at port } 2 \text {, no } \\
\text { heatsink }\end{array}$ & 2.07 & -30.5376 \\
\hline Excitation at port1, 50ohm at port2, no heatsink & 1 & / \\
\hline Excitation at port1 and port 2, no heatsink & 2.06 & -18.4650 \\
\hline \multirow{2}{*}{$\begin{array}{l}\text { Excitation at port } 1 \text { and port } 2 \text {, with } \\
60 \mathrm{~mm} \times 60 \mathrm{~mm} \times 39 \mathrm{~mm} \text { heatsink }\end{array}$} & 1.81 & -13.1758 \\
\hline & 3.26 & -8.2155 \\
\hline \multirow{2}{*}{$\begin{array}{l}\text { Excitation at port } 1 \text { and port } 2 \text {, with } \\
83 \mathrm{~mm} \times 64 \mathrm{~mm} \times 38 \mathrm{~mm} \text { heatsink }\end{array}$} & 1.78 & -10.5972 \\
\hline & 3.18 & -10.7900 \\
\hline \multirow{2}{*}{$\begin{array}{l}\text { Excitation at port } 1 \text { and port } 2 \text {, with } \\
101 \mathrm{~mm} \times 76 \mathrm{~mm} \times 32 \mathrm{~mm} \text { heatsink }\end{array}$} & 1.79 & -10.8090 \\
\hline & 3.16 & -10.4744 \\
\hline \multirow{2}{*}{ Measurement Setup Environment } & \multicolumn{2}{|c|}{ Reflection Coefficient } \\
\hline & $\mathrm{GHz}$ & $\mathrm{dB}$ \\
\hline $\begin{array}{l}\text { Excitation at port1, open circuit at port2, no } \\
\text { heatsink }\end{array}$ & 2.1625 & -19.66 \\
\hline Excitation at port1, 50ohm at port2, no heatsink & 2.185 & -25.41 \\
\hline Excitation at port1 and port2, no heatsink & 2.2075 & -28.65 \\
\hline \multirow{2}{*}{$\begin{array}{l}\text { Excitation at port } 1 \text { and port } 2, \text { with } \\
60 \mathrm{~mm} \times 60 \mathrm{~mm} \times 39 \mathrm{~mm} \text { heatsink }\end{array}$} & 1.8775 & -9.404 \\
\hline & 3.6175 & -11.80 \\
\hline \multirow{2}{*}{$\begin{array}{l}\text { Excitation at port } 1 \text { and port } 2 \text {, with } \\
83 \mathrm{~mm} \times 64 \mathrm{~mm} \times 38 \mathrm{~mm} \text { heatsink }\end{array}$} & 1.81 & -6.985 \\
\hline & 3.5425 & -16.80 \\
\hline \multirow{2}{*}{$\begin{array}{l}\text { Excitation at port } 1 \text { and port } 2 \text {, with } \\
101 \mathrm{~mm} \times 76 \mathrm{~mm} \times 32 \mathrm{~mm} \text { heatsink }\end{array}$} & 1.8325 & -8.139 \\
\hline & 3.505 & -12.86 \\
\hline
\end{tabular}

TABLE IV REFLECTION COEFFICIENT COMPARISON BETWEEN SIMULATION AND MEASUREMENT WITH DIFFERENT CONFIGURATION AT PORT2

\begin{tabular}{|c|c|c|}
\hline \multirow{2}{*}{ Simulation Setup Environment } & \multicolumn{2}{|c|}{ Reflection Coefficient } \\
\hline & $\mathrm{GHz}$ & $\mathrm{dB}$ \\
\hline $\begin{array}{l}\text { Excitation at port } 2 \text {, open circuit at port } 1, \text { no } \\
\text { heatsink }\end{array}$ & 2.14 & -4.9912 \\
\hline Excitation at port2, 50ohm at port1, no heatsink & 1 & 1 \\
\hline Excitation at port1 and port2, no heatsink & 2.05 & -3.7247 \\
\hline \multirow{2}{*}{$\begin{array}{l}\text { Excitation at port } 1 \text { and port } 2 \text {, with } \\
60 \mathrm{~mm} \times 60 \mathrm{~mm} \times 39 \mathrm{~mm} \text { heatsink }\end{array}$} & 1.81 & -3.2600 \\
\hline & 3.25 & -7.4557 \\
\hline \multirow{2}{*}{$\begin{array}{l}\text { Excitation at port } 1 \text { and port } 2, \text { with } \\
83 \mathrm{~mm} \times 64 \mathrm{~mm} \times 38 \mathrm{~mm} \text { heatsink }\end{array}$} & 1.78 & -2.6925 \\
\hline & 3.17 & -7.5719 \\
\hline \multirow{2}{*}{$\begin{array}{l}\text { Excitation at port } 1 \text { and port } 2 \text {, with } \\
101 \mathrm{~mm} \times 76 \mathrm{~mm} \times 32 \mathrm{~mm} \text { heatsink }\end{array}$} & 1.79 & -2.9692 \\
\hline & 3.15 & -7.0291 \\
\hline \multirow{2}{*}{ Measurement Setup Environment } & \multicolumn{2}{|c|}{ Reflection Coefficient } \\
\hline & $\mathrm{GHz}$ & $\mathrm{dB}$ \\
\hline $\begin{array}{l}\text { Excitation at port2, open circuit at port1, no } \\
\text { heatsink }\end{array}$ & 2.1175 & -9.831 \\
\hline Excitation at port $2,50 \mathrm{ohm}$ at port1, no heatsink & 2.1625 & -4.771 \\
\hline Excitation at port1 and port2, no heatsink & 2.2075 & -3.089 \\
\hline \multirow{2}{*}{$\begin{array}{l}\text { Excitation at port } 1 \text { and port } 2 \text {, with } \\
60 \mathrm{~mm} \times 60 \mathrm{~mm} \times 39 \mathrm{~mm} \text { heatsink }\end{array}$} & 1.87 & -2.561 \\
\hline & 3.1225 & -9.635 \\
\hline \multirow{2}{*}{$\begin{array}{l}\text { Excitation at port } 1 \text { and port } 2 \text {, with } \\
83 \mathrm{~mm} \times 64 \mathrm{~mm} \times 38 \mathrm{~mm} \text { heatsink }\end{array}$} & 1.81 & -2.507 \\
\hline & 3.085 & -13.50 \\
\hline \multirow{2}{*}{$\begin{array}{l}\text { Excitation at port } 1 \text { and port } 2 \text {, with } \\
101 \mathrm{~mm} \times 76 \mathrm{~mm} \times 32 \mathrm{~mm} \text { heatsink }\end{array}$} & 1.81 & -2.841 \\
\hline & 3.0925 & -13.38 \\
\hline
\end{tabular}

\section{B. Input Impedance}

For the situation of without heatsink, input impedance is measured at both Port1 and Port2. Data of real and imaginary part collected is re-plotted with Matlab into the same figure, Figure 9. and Figure 10 In TABLE III, resonant frequency of Port1 is given as $2.2075 \mathrm{GHz}$. Accordingly in the impedance of Port1, the real part is 70.2184 and the imaginary part is 3.59488. As the source and transmission line used are designed with $50 \mathrm{ohm}$, when the model impedance is around 50 in real part and 0 in imaginary part, it is known as reflectionless impedance matching. The result gives a good match for definition. For Port2, resonant frequency is at $4.80 \mathrm{GHz}$ from simulation which is outside the measurement frequency range. Impedance measurement result of Port2 shows nothing for resonating proved a match in the other way. Consequently, it also confirms the concurrence of simulation and measurement.

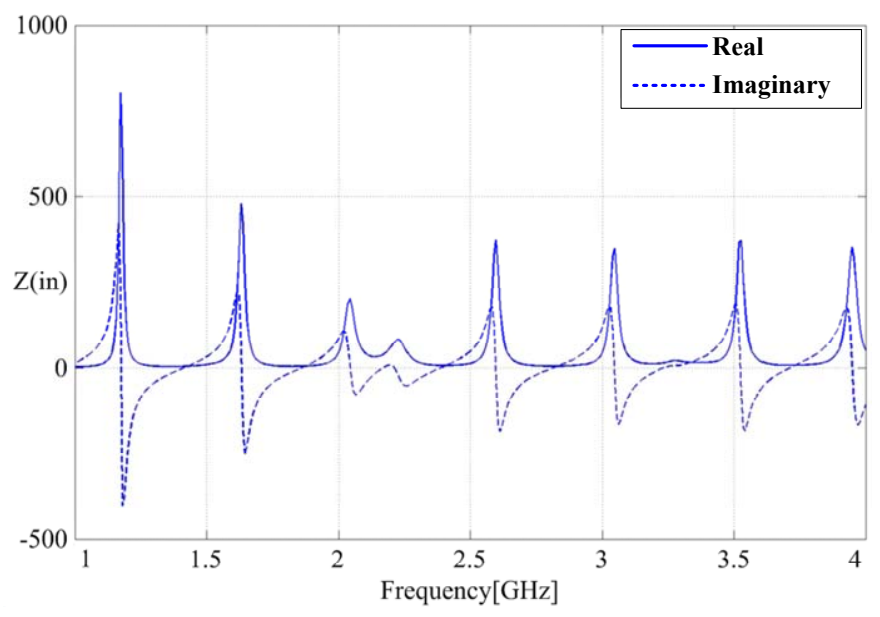

Figure 9. Input impedance of Port1 without heatsink

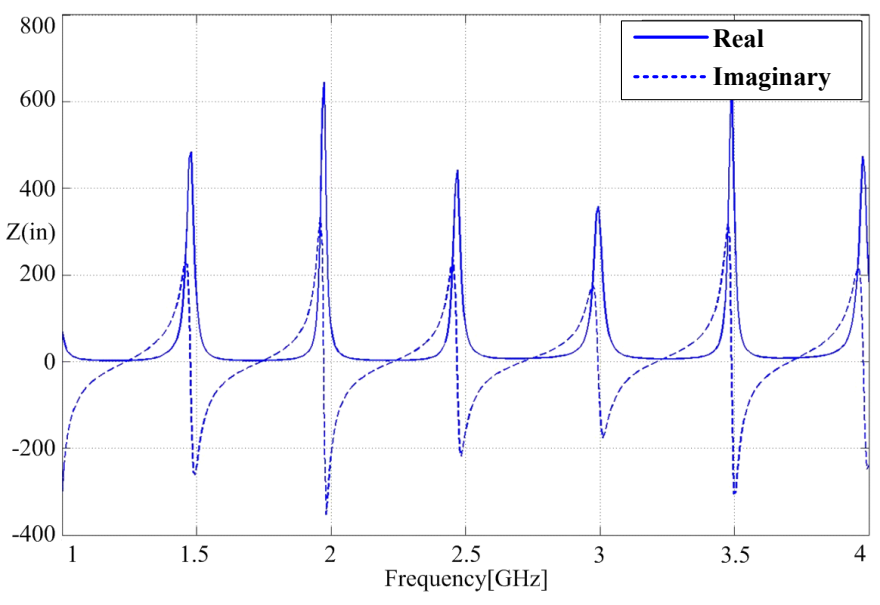

Figure 10. Input impedance of Port2 without heatsink

\section{Far-field Distribution}

Far-field simulation gives an idea of how the field distributed around the model. From Figure 11 to Figure 12, radiation patterns for far-field are presented among model without heatsink and with three different heatsinks. In the figures, Theta is the angle from the $\mathrm{x}$-axis and Phi is the angle from the origin in $\mathrm{z}$ direction. In Figure 13, it indicates that radiation leaves the model on the top and then separates when frequency goes much high, which means radiations from two probes are cancelling each other at the position of crossing. when a heatsink is mounted, it reflects much of radiation backward as illustrated from Figure 14 to Figure 16. When heatsink on the top is expanded, the scope of reflection is spread consequently.

TABLE $\mathrm{V}$ gives a comparison of radiation efficiency and gain collected from simulation with different heatsink configurations. 


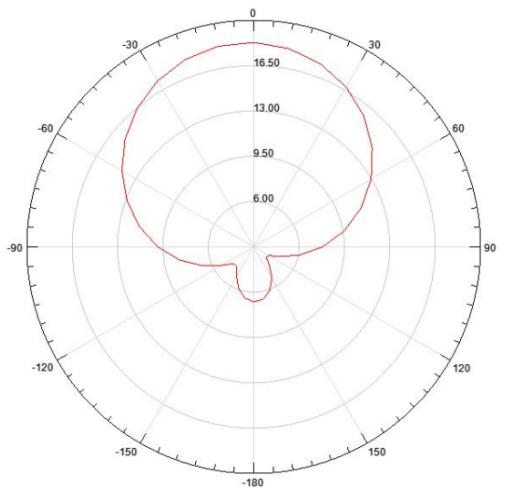

(a) Radiating at $2.05 \mathrm{GHz}\left(\mathrm{Phi}=0,0 \leqq\right.$ Theta $\left.\leqq 360^{\circ}\right)$

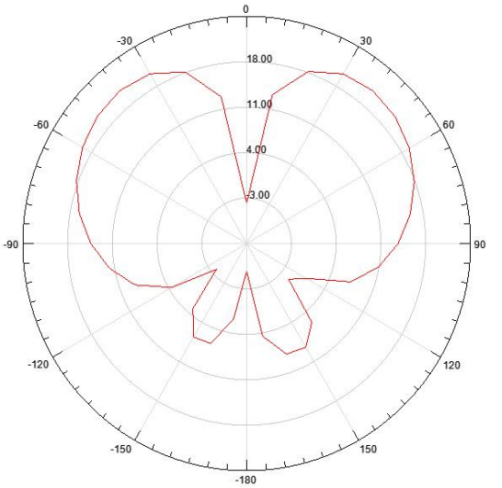

(b) Radiating at $4.90 \mathrm{GHz}\left(\mathrm{Phi}=0,0 \leqq\right.$ Theta $\left.\leqq 360^{\circ}\right)$

Figure 13. Model without heatsink in $\mathrm{dB}(\mathrm{rET}$ Total)

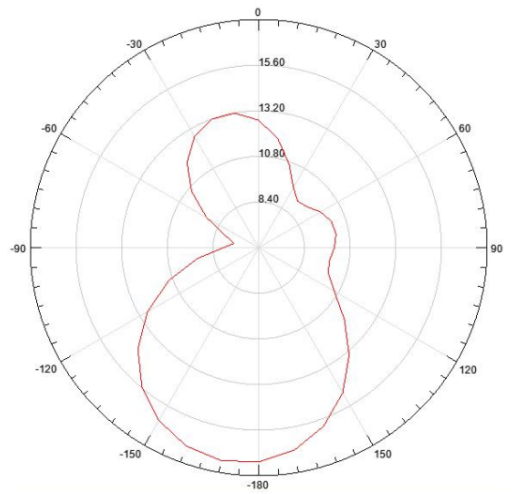

(a) Radiating at $1.81 \mathrm{GHz}\left(\mathrm{Phi}=0,0 \leqq \mathrm{Theta} \leqq 360^{\circ}\right)$

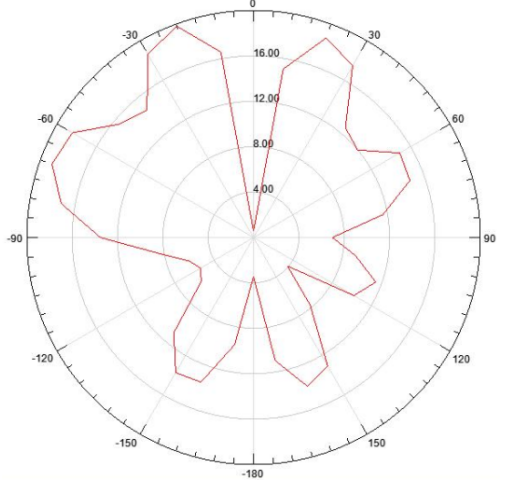

(b) Radiating at $5.51 \mathrm{GHz}\left(\mathrm{Phi}=0,0 \leqq \mathrm{Theta} \leqq 360^{\circ}\right.$ )

Figure 14. Model with $60 \mathrm{~mm} \times 60 \mathrm{~mm} \times 39 \mathrm{~mm}$ heatsink in $\mathrm{dB}(\mathrm{rET}$ Total $)$

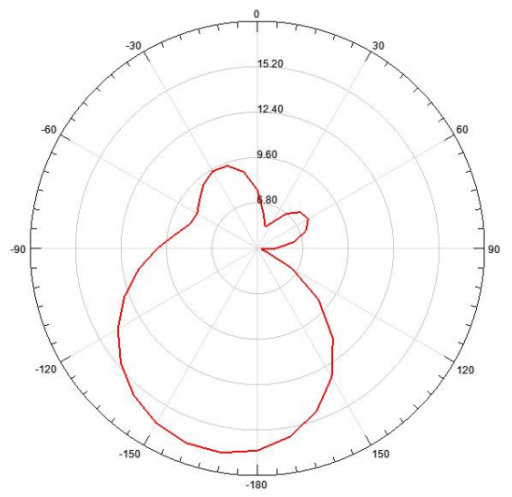

(a) Radiating at $1.78 \mathrm{GHz}\left(\mathrm{Phi}=0,0 \leqq \mathrm{Theta} \leqq 360^{\circ}\right)$

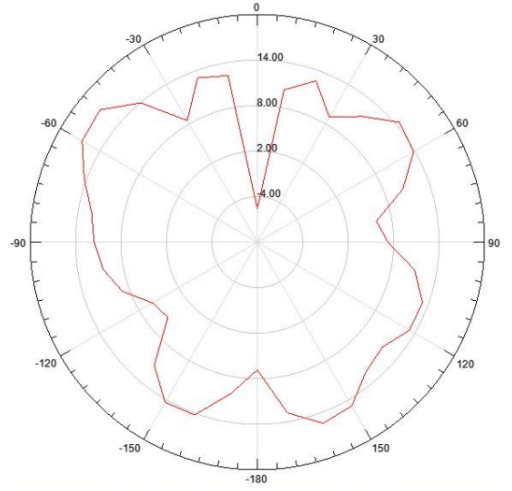

(b) Radiating at $5.40 \mathrm{GHz}\left(\mathrm{Phi}=0,0 \leqq \mathrm{Theta} \leqq 360^{\circ}\right)$

Figure 15 . Model with $83 \mathrm{~mm} \times 64 \mathrm{~mm} \times 38 \mathrm{~mm}$ heatsink in $\mathrm{dB}(\mathrm{rETotal})$

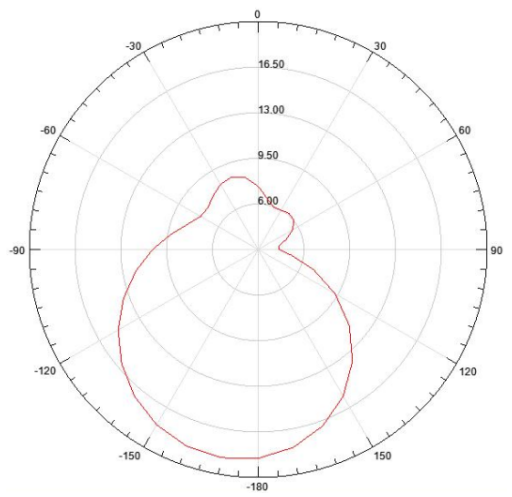

(a) Radiating at $1.79 \mathrm{GHz}\left(\mathrm{Phi}=0,0 \leqq \mathrm{Theta} \leqq 360^{\circ}\right)$

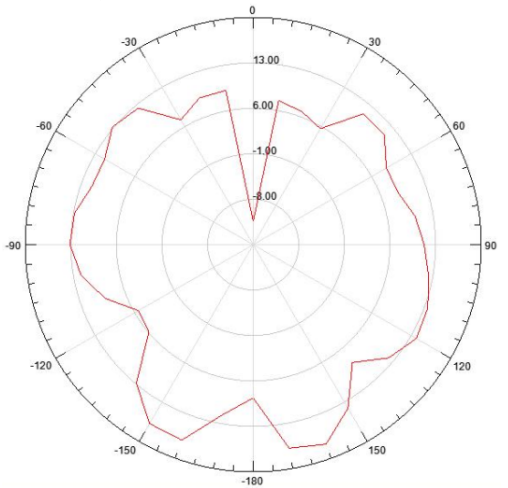

(b) Radiating at $5.38 \mathrm{GHz}\left(\mathrm{Phi}=0,0 \leqq \mathrm{Theta} \leqq 360^{\circ}\right)$

Figure 16 . Model with $101 \mathrm{~mm} \times 76 \mathrm{~mm} \times 32 \mathrm{~mm}$ heatsink in $\mathrm{dB}(\mathrm{rETotal})$ 
TABLE V RADIATION EFFICIENCY AND GAIN

\begin{tabular}{|l|l|l|}
\hline \multicolumn{2}{|l|}{ Radiation Efficiency } & Peak Gain( dBi) \\
\hline Without Heatsink & 2.7366 \\
\hline At $2.05 \mathrm{GHz}$ & 0.5882 & 2.4199 \\
\hline At $4.90 \mathrm{GHz}$ & 0.6656 & 2.7712 \\
\hline With $\mathbf{6 0 m m} \times \mathbf{6 0} \mathbf{m m} \times \mathbf{3 9 m m}$ Heatsink \\
\hline At $1.81 \mathrm{GHz}$ & 0.7321 & 3.1416 \\
\hline At $5.51 \mathrm{GHz}$ & 0.6841 & 3.0490 \\
\hline With $\mathbf{8 3 m m} \times \mathbf{6 4 m m} \times \mathbf{3 8 m m}$ Heatsink \\
\hline At $1.78 \mathrm{GHz}$ & 0.7433 & 2.2706 \\
\hline At $5.40 \mathrm{GHz}$ & 0.5872 & 3.6336 \\
\hline with $\mathbf{1 0 1} \mathbf{m m} \times \mathbf{7 6} \mathbf{m m} \times \mathbf{3 2} \mathbf{m m}$ Heatsink \\
\hline At $1.79 \mathrm{GHz}$ & 0.7262 & 2.4809 \\
\hline At $5.38 \mathrm{GHz}$ & 0.6926 & \\
\hline
\end{tabular}

\section{Near-field Measurement}

Near-field measurement is undertaken in a semi-anechoic chamber. However, although in a relative noiseless environment, some noises are still captured from RF generator, they are $2.801 \mathrm{GHz}$ with $-49.79 \mathrm{dBm}, 2.921 \mathrm{GHz}$ with -44.87 $\mathrm{dBm}$ and $3.000 \mathrm{GHz}$ with $-44.97 \mathrm{dBm}$. According to the radiation patterns given in far field, the interested measurement positions for near-field are at the top of model when heatsink is not mounted and the bottom for model with heatsink. In this paper, specific antenna is fixed at proper place $5 \mathrm{~mm}$ space in parallel with upper surface of model and a power measurement result is presented in Figure 17.

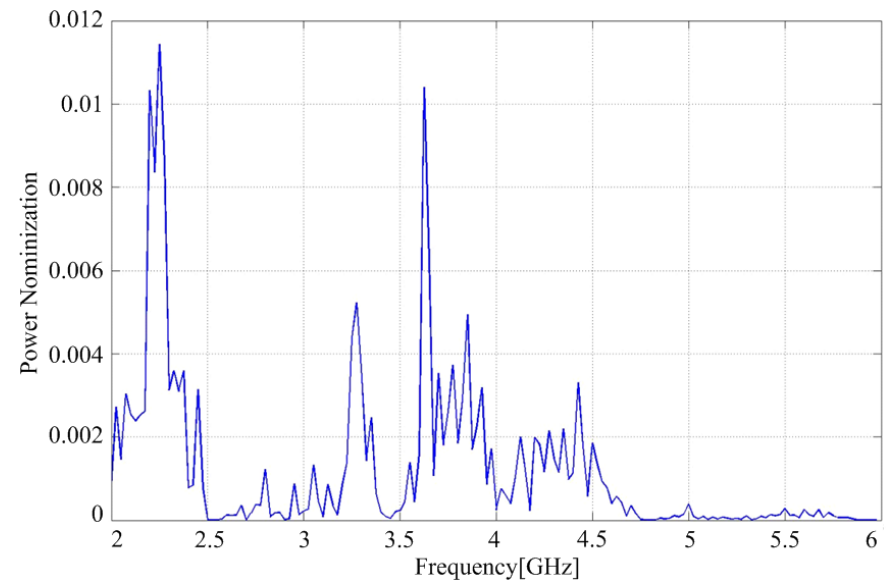

Figure 18. Power measured in chamber without heatsink and normalisated by $10 \mathrm{~mW}$ (top)

\section{CONCLUSION}

In this paper, an upgraded simulation model for dual die structure has been presented and verified with various measurement. S11 measurement results confirm the coincidence between the simulation and measurement. The resonant frequency of model without heatsink in the range of 2 $\mathrm{GHz}$ to $4 \mathrm{GHz}$ is measured at $2.2075 \mathrm{GHz}$ with $-28.65 \mathrm{~dB}$, comparing with simulation result of $2.06 \mathrm{GHz}$ with $-18.465 \mathrm{~dB}$. There is also a higher resonant frequency around $5 \mathrm{GHz}$ that can not be measured since it beyond the maximum measurement range of equipment and $\mathrm{CPU}$ working frequency as well.

According to the radiation patterns given in far field, specific antenna is fixed at proper places, $5 \mathrm{~mm}$ space in parallel with upper and bottom surface of model respectively. Corresponding field strength and absolute power are collected for reference. After all, the upgraded model of dual die CPU with heatsink is verified with consistency between simulation and measurement. The whole work offers a strong support on the proposal of a new benchmark of challenging problem for EMC.

\section{REFERENCES}

[1] IEEE/EMC TC-9 and ACEM website. [Online]. Available: http://aces.ee.olemiss.edu/.

[2] Junwei Lu and Xiao Duan, "EMC computer modelling techniques for CPU heat sink simulation," 3rd International Conference, Proceedings on Computational Electromagnetics and Its Applications (ICCEA 2004), Nov 2004, pp. 272-275.

[3] Junwei Lu and Francis Dawson, "EMC Computer Modeling Techniques for CPU Heat Sink Simulation," IEEE Transactions on Magnetics, Oct 2006, pp. 3171-3173.

[4] Junwei Lu and Xiao Duan, "Comparative Analysis of Intel Pentium 4 and IEEE/EMC TC-9/ACEM CPU Heat Sinks," EMC IEEE International Symposium on Electromagnetic Compatibility, July 2007, pp. 1-6.

[5] Boyuan Zhu, Junwei $\mathrm{Lu}$ and Erping Li, "Electromagnetic Radiation Study of Intel Dual Die CPU with Heatsink," the 8th International Symposium on Antennas, Propagation, and EM Theory (ISAPE2008), Nov 2008, pp. $1259-1262$.

[6] Boyuan Zhu, Junwei Lu, Erping Li and Takashi Iwashita, "EMC Modeling of an Intel Dual Die CPU," International Symposium on Electromagnetic Compatibility, Kyoto, July 2009, pp.521-524.

[7] "Intel® CoreTM2 Extreme Quad-Core Processor QX6000 Sequence and Intel ${ }^{\circledR}$ CoreTM2 Quad Processor Q6000 Sequence Datasheet", Intel Corporation, pp. 31-34, Aug 2007.

[8] Nazifa Mariam, "Design of Coaxial Fed Microstrip Antenna for LEO Satellites," WOCN '08. 5th IFIP International Conference on Wireless and Optical Communications Networks, May 2008, pp. 1-5.

[9] Tom's Hardware [Online]. Available: http://www.tomshardware.com/ reviews/intel-penryn-4ghz-air-cooling, 1712-5.html.

[10] [Online]. Available: http://www.home.aglient.com/upload/cmc upload /All/NSI-near-far.pdf. 